\title{
Cardiac Care of Patients with Cardiac Amyloidosis
}

\author{
Osnat Itzhaki Ben Zadok ${ }^{a, b}$ Ran Kornowski ${ }^{a, b}$ \\ ${ }^{a}$ Department of Cardiology, Rabin Medical Center, Petah Tikva, Israel; ${ }^{b}$ Sackler Faculty of Medicine, \\ Tel Aviv University, Tel Aviv, Israel
}

\section{Keywords}

Cardiac amyloidosis $\cdot$ Immunoglobulin light chain amyloidosis · Transthyretin amyloidosis

\section{Abstract}

Cardiac amyloidosis, the majority of cases of which are due to immunoglobulin light chain amyloidosis (AL) and transthyretin amyloidosis (ATTR), affects different aspects of the heart and cardiovascular system. Amyloid-induced cardiomyopathy, clinically manifesting with heart failure and electrophysiological abnormalities, has distinct characteristics compared to non-amyloid cardiomyopathies. Accordingly, specific management strategies are required. This paper will review the cardiovascular manifestations of patients with cardiac amyloidosis and their suggested treatment strategies, emphasizing the importance of multidisciplinary care.

(c) 2020 S. Karger AG, Basel

\section{Introduction}

The entity of cardiac amyloidosis (CA) is increasingly recognized nowadays mainly due to improved diagnostic tools and novel treatment options. However, CA is still often misdiagnosed, resulting in delayed diagnosis and a dismal prognosis. Amyloid-induced cardiomyopathy results from cytotoxic circulating amyloid oligomers and amyloid fibrils which distort the structure of the cardiac tissue, causing impaired contractility and organ dysfunction $[1,2]$.

Although amyloid diseases are numerous, the pattern of systemic deposition varies according to the specific type of misfolded protein. Cardiac involvement is evident predominantly in 2 types of amyloid diseases, i.e., immunoglobulin light chain amyloidosis (AL) and transthyretin amyloidosis (ATTR). The minority of CA cases $(<5 \%)$ are attributed to amyloid A, apolipoprotein AI, or heavy chain or atrial natriuretic peptide (ANP). Both AL-CA and ATTR-CA share structural cardiac similarities with the hallmark of diffused biventricular and biatrial thickening. 
Table 1. Major recommendations for the cardiovascular care of patients with CA

Management recommendations

\begin{tabular}{|c|c|}
\hline & Management recommendations \\
\hline \multirow{2}{*}{$\begin{array}{l}\text { General } \\
\text { lifestyle } \\
\text { measures }\end{array}$} & Low-salt diet \\
\hline & $\begin{array}{l}\text { Avoid volume overload or dehydration } \\
\text { (recommend home weight measurements) }\end{array}$ \\
\hline \multirow{3}{*}{$\begin{array}{l}\text { Postural } \\
\text { hypotension }\end{array}$} & Suspect and test for orthostatic hypotension \\
\hline & Recommend slow postural changes \\
\hline & Consider midodrine (slow uptitration) \\
\hline \multirow[t]{2}{*}{ Heart failure } & $\begin{array}{l}\text { Use diuretics (mainly loop diuretics and } \\
\text { spironolactone) }\end{array}$ \\
\hline & $\begin{array}{l}\text { Avoid } \beta \text {-blockers, nondihydropyridine calcium } \\
\text { channel blockers, and renin-angiotensin inhibi- } \\
\text { tors }\end{array}$ \\
\hline \multirow[t]{4}{*}{$\begin{array}{l}\text { Atrial } \\
\text { arrhythmias }\end{array}$} & $\begin{array}{l}\text { Order a 24-h electrocardiogram (Holter ECG) } \\
\text { following CA diagnosis and when suggested by } \\
\text { history (palpitations and chest pain) }\end{array}$ \\
\hline & Aim for rhythm control when possible \\
\hline & TEE-guided direct current cardioversion \\
\hline & Low threshold for initiation of anticoagulation \\
\hline $\begin{array}{l}\text { Ventricular } \\
\text { arrhythmias }\end{array}$ & $\begin{array}{l}\text { Consider ICD implantation when appropriate } \\
\text { according to consensus guidelines }\end{array}$ \\
\hline $\begin{array}{l}\text { Conduction } \\
\text { abnormalities }\end{array}$ & $\begin{array}{l}\text { Low threshold for pacemaker implantation } \\
\text { when presyncope/syncope is suggested by his- } \\
\text { tory }\end{array}$ \\
\hline $\begin{array}{l}\text { Thrombo- } \\
\text { prophylaxis }\end{array}$ & $\begin{array}{l}\text { Consider concomitant with immunomodulatory } \\
\text { drugs }\end{array}$ \\
\hline
\end{tabular}

TEE, transesophageal echocardiogram.

This paper will review the cardiovascular manifestations of patients with CA and their suggested management (Table 1).

\section{CA Phenotype of Heart Failure with a Preserved Ejection Fraction}

\section{Diastolic Dysfunction in CA}

Patients with CA comply with the definition of heart failure with a preserved ejection fraction, which encompasses signs and symptoms of heart failure, diastolic dysfunction and $\mathrm{EF} \geq 50 \%[3,4]$. However, even though the measured left ventricular (LV) ejection fraction is preserved or even in the normal reference range, the stroke volume and cardiac output are reduced due to a diminished LV end-diastolic volume and impaired LV diastolic function [5]. Indeed, the pathophysiological hallmark of CA is diastolic dysfunction, while ventricular systolic dysfunction is usually apparent in more progressed, advanced stages of the disease. Amyloid infiltration of the ventricles results in stiff ventricular walls with poor compliance and elevated filling pressures. Both AL-CA and ATTR-CA demonstrate the appearance of concentric hypertrophy, although a subgroup of patients with CA (particularly ATTR-CA) may present with asymmetric septal hypertrophy mimicking hypertrophic cardiomyopathy [6]. Importantly, the echocardiographic finding of LV hypertrophy in patients with CA is misleading, since the LV thickening is due to infiltrating amyloid fibrils rather than true myocyte hypertrophy, unless compensatory myocyte hypertrophy occurs $[7,8]$. The mitral LV inflow pattern ranges from abnormal relaxation pattern in early disease (to be differentiated from a physiologic ageing manifestation) to the more specific restrictive filling pattern in severe, advanced disease. Diminished septal and lateral tissue Doppler velocities are also typical in amyloid heart disease [9]. An average tissue Doppler mitral annular S' of $<6 \mathrm{~cm} / \mathrm{s}$ was found to be a sensitive measure among patients with severe aortic stenosis undergoing transcutaneous aortic valve replacement that should prompt subsequent additional testing for ATTR-CA [10].

Clinically, progressive diastolic dysfunction manifests as dyspnea on exertion, orthopnea, and paroxysmal nocturnal dyspnea, and right ventricular heart failure may present with symptoms of peripheral edema and ascites. Peripheral edema in AL amyloidosis may also be due the use of steroids or to the hypoalbuminemia associated with nephrotic syndrome, or it may result from diflunisal treatment in ATTR amyloidosis. On physical examination, a Kussmaul sign is frequently apparent, showing a paradoxical inspiratory rise in jugular venous pressure. Contrary to heart failure resulting from other etiologies, third and fourth heart sounds are uncommon in CA [7].

\section{Pharmacological Heart Failure Treatments in CA}

The pharmacological treatment of CA is divided into amyloid-suppressive therapies and cardiac-specific treatments. Although medical therapy in CA does not rely on high-quality evidence, we will review opinion-based management strategies [7, 11-13] and our own clinical practice-based experience.

The mainstay of treatment for CA is salt restriction $(<6 \mathrm{~g} /$ day) [3] and diuretics, both aimed at relief of the volume overload [13]. Patients often require the combi- 
nation of a loop diuretic (furosemide or torsemide) and a mineralocorticoid receptor antagonist (spironolactone or eplerenone). Moreover, a mineralocorticoid receptor antagonist is of potential value for these patients due to its beneficial effect in the treatment of diastolic dysfunction in nonamyloid cardiomyopathies [14]. However, it should be noted that due to the restrictive physiology of $\mathrm{CA}$ an adequate stroke volume depends on maintenance of relatively high LV filling pressures. Moreover, overdiuresis may lead to hypotension and acute kidney injury, especially in this group of patients with systemic amyloidosis who share a tendency toward orthostatic hypotension and renal dysfunction. Caution should be exercised when mineralocorticoid receptor antagonists are used in patients with impaired renal function and in those with serum potassium levels $>5.0 \mathrm{mmol} / \mathrm{L}$ [3]. Thus, the caring physician is often challenged with a narrow therapeutic window, aiming for the optimal volume balance.

Neurohormonal Pharmacotherapy in CA. Traditional neurohormonal inhibition treatment ( $\beta$-blockers and renin-angiotensin system inhibitors), used successfully in nonamyloid cardiomyopathies, are frequently poorly tolerated or nonefficacious in CA $[7,12,15]$.

$\beta$-Blockers that carry negative ionotropic and chronotropic effects frequently reduce the cardiac output and result in significant hypotension. This is probably due to blunting of the compensatory tachycardic response to the fixed stroke volume and to the vasodilatation from autonomic dysfunction [11]. Moreover, $\beta$-blockers can also worsen bradycardia and mitigate heart block in this population that is already prone to electrical conduction abnormalities. Thus, the use of $\beta$-blockers should be limited to selected patients with atrial fibrillation (AF) and a rapid ventricular rate nonresponsive to other rate control measures $[7,16]$.

Angiotensin-converting enzyme inhibitors and angiotensin-receptor blockers are often poorly tolerated even in moderated doses due to a low cardiac output, orthostatic hypotension, or autonomic neuropathy [7, 17]. Again, the frequent coexistence of renal dysfunction may also discourage the use of these drugs, although it may be carefully considered in cases of severe proteinuria and nephrotic syndrome.

Nondihydropyridine calcium channel blockers (such as verapamil and diltiazem) have been shown to bind avidly to amyloid fibrils and thus are contraindicated in CA due to the risk of worsening heart failure, profound hypotension, and syncope $[7,18-20]$.

Doxycycline and Tauroursodeoxycholic Acid. Evidence regarding the use of doxycycline in CA is conflicting.
Doxycycline is a tetracycline antibiotic that has been shown to interfere with amyloid fibril formation in transgenic mouse models of AL and ATTR amyloidosis [21, 22]. In a retrospective study investigating 30 patients with AL CA, the addition of doxycycline to standard chemotherapy was associated with improved survival [23]. Tauroursodeoxycholic acid is a bile acid with antiapoptotic and antioxidant properties that has been shown to reduce ATTR-associated aggregates [22]. The combination of both doxycycline and tauroursodeoxycholic acid has been studied in 2 small studies of patients with ATTRCA. A phase 2 open label study showed cardiac stability in a cohort of 7 patients who completed 12 months of follow-up [24]. A more recent study in 53 patients with ATTR-CA showed no progression in pro B-type natriuretic peptide (NT-proBNP) and improvement in the global longitudinal strain on echocardiography, yet with a significant mortality bias $[25,26]$. In conclusion, when considering the relatively weak evidence of a beneficial effect along with the noninnocent safety profile (a reported $11 \%$ of dermatologic and gastrointestinal side effects) [26], one should carefully consider the use of this combination in the treatment of CA until more solid data from larger phase 3 randomized trials are available.

\section{Therapy Surveillance}

Surveillance of the cardiac response during amyloid-targeted therapy is complicated, since a reduction of the LV wall thickness or significant improvement in the ejection fraction is infrequently apparent following treatment [27, 28]. However, improvements in the global longitudinal strain can be seen despite the lack of structural changes on echocardiogram $[28,29]$. According to the recently published Expert Consensus Recommendations for Multimodality Imaging in Cardiac Amyloidosis, it is reasonable to use echocardiography to monitor disease progression and response to therapy in CA [30]. In addition, cardiovascular magnetic resonance assessment of LV wall thickness, LV mass, and particularly extracellular volume is emerging as a pivotal tool to assess disease progression and response to therapy [30]. Importantly, NT-proBNP and high-sensitivity cardiac troponin $\mathrm{T}$ (hs-cTnT) are independent prognostic markers in patients with AL and ATTR-CA and are used for disease staging [31-33]. Moreover, these biomarkers are used to define the cardiac response to treatment and disease progression in AL amyloidosis [34]. Until more data accumulates regarding the role of imaging in assessment of the response to therapy, the combination of comprehensive cardiac imaging and biomarkers surveillance is a key for disease monitoring in CA. 
Implantation of an LV Assist Device in CA

Patients with CA are nonoptimal candidates for the implantation of LV assist devices due to 2 major inherent negative prognostic characteristics: a small LV cavity and a dysfunctional right ventricle [7]. A report from the Mayo Clinic of 9 patients with ATTR-CA demonstrated similar 1-year survival rates after LV assist device implantation between amyloidosis and nonamyloidosis patients, but with poorer survival if the LV end-diastolic dimension was $<46 \mathrm{~mm}$ [35]. More real-life outcome data are sparse.

\section{Heart Transplantation in $C A$}

Heart transplantation (HT) in AL-CA was previously considered a contraindication because of potential risks regarding amyloid infiltration of the transplanted heart and systemic amyloid involvement [36]. However, advances in the long-term control of systemic amyloidosis made HT possible in carefully selected patients with outcomes comparable to those in other restrictive cardiomyopathies (an average of 45-60\% 5-year mortality) [37-39].

According to the ISHLT recommendations [40], selected patients with heart failure due to AL amyloidosis who are not candidates for disease-specific therapies due to cardiovascular compromise may be considered for HT in experienced centers. Autologous stem cell transplantation should be planned as soon as clinically feasible after recovery from HT, mostly 6-8 months after HT $[13,40$, 41]. The most common cause of death after HT/autologous stem cell transplantation is the recurrence of light chain production and end-organ disease, including cardiac recurrence [40]. Patients with ATTR-CA, especially younger patients, may also be considered for HT. Either way, amyloid involvement of extra-cardiac organs must be carefully evaluated before HT, and severe organ dysfunction should be considered a contraindication to proceeding with transplantation $[13,42]$. In conclusion, HT in CA is now feasible but requires the careful evaluation of patients and the collaborations between cardiovascular and hematology teams.

\section{Electrophysiological Abnormalities in CA}

\section{Atrial Arrhythmias}

The atria are classically involved in CA due to amyloid deposition and interatrial septal thickening [43], and atrial dilation may result from elevated LV filling pressures [16]. These mechanisms ultimately contribute to the development of atrial arrhythmias, especially AF [43], and thus a 24-h electrocardiogram (Holter ECG) is recom- mended following the diagnosis of CA [13] and whenever such arrhythmias are clinically suspected.

Atrial arrhythmias are poorly tolerated in CA mostly due to the rapid, frequently irregular ventricular rates which further compromise ventricular filling under conditions of diastolic dysfunction. Patients usually present with an exacerbation of heart failure symptoms. Another possible mechanism for the clinical deterioration during AF is the loss of atrial contractility, although its contribution is questionable since atrial contractility is often diminished in CA even in sinus rhythm [16].

Rate Control in CA. Management of AF is particularly complicated in CA. Classic rate control drugs are usually avoided in CA due their negative ionotropic ( $\beta$-blockers and calcium channel blockers) or presumably toxic effects (digoxin). However, as noted above, cautious use of low-dosage $\beta$-blockers may be clinically required $[17,44]$. Another rate control option is amiodarone, which is usually well tolerated $[7,15,16]$, and there are also reports describing the use of dofetilide $[7,16]$.

Despite the common practice of considering digoxin as an absolute contraindication in patients with CA, mainly due to in vitro reports of increased toxicity [45], the clinical significance of this finding is unclear and its use in low doses is usually tolerated [16]. A retrospective analysis of $107 \mathrm{AL}$ patients treated with digoxin demonstrated the development of significant arrhythmias in $11 \%$ of the cases, almost exclusively in newly diagnosed patients [46]. The dose of digoxin should be adjusted according to serum trough levels, with the aim of lowering the therapeutic drug range, generally with a reduced loading dose [32].

Rhythm Control in CA. A recent study described direct current cardioversion procedural outcomes in patients with CA [47]. Although the success rate of restoration of the sinus rhythm was high, tachyarrhythmias and bradyarrhythmias complicating direct current cardioversion were significantly more frequent in CA patients compared with control patients ( 14 vs. $0 \%$ ). However, the successful cardioversion and atrial arrhythmia recurrence rates were similar in CA patients and control patients.

Rhythm control by ablation is another treatment strategy for atrial arrhythmias. Results from a small cohort of patients undergoing ablation for atrial tachycardia or AF demonstrated a high recurrence rate (83\% 1-year recurrence rate for CA patients compared to $25 \%$ in the nonCA, persistent AF group) [48]. Atrioventricular (AV) nodal ablation has also been shown to offer symptomatic improvement in CA patients [49], though at the cost of AV desynchrony. 
Anticoagulation for Atrial Arrhythmias. Anticoagulation is frequently required in patients with CA due to the high risk of intracardiac thrombus formation. In a study describing the findings of 116 autopsies, intracardiac thrombus was detected in $33 \%$ of patients with CA compared to none in the control group [50]. The combination of AL amyloidosis and AF was associated with a very high risk for thromboembolism $(\mathrm{OR}=55.0$; 95\% CI 8.11,131.4) [50]. Despite an inherent concern regarding bleeding [51], anticoagulation is usually well tolerated and should be used for all atrial arrhythmias $[7,16]$. The incidence of intracardiac thrombi during transesophageal studies in those receiving versus not receiving therapeutic anticoagulants was much lower (13 vs. $37 \%$ ) [52].

Importantly, intracardiac thrombus was detected in $28 \%$ of CA patients referred for transesophageal guided direct cardioversion, including patients who did not require transesophageal guidance per guidelines (either had a therapeutic level of anticoagulation for $>3$ weeks or arrhythmia onset $<48 \mathrm{~h}$ before the planned cardioversion) [47]. Thus, transesophageal echocardiography should strongly be considered before direct cardioversion in all patients with CA, regardless of the duration of arrhythmia or the therapeutic level of anticoagulation [47, 53].

Patients with CA in sinus rhythm are also at risk for intracardiac thrombus.

As demonstrated by atrial strain imaging, the atria in the amyloid heart act as a simple conduit throughout the cardiac cycle due to both impaired atrial shortening and a failure to expand during filling $[7,54]$. This, combined with the already low cardiac output and atrial amyloid involvement, sets the stage for thrombus formation despite sinus rhythm $[7,55]$. Therefore, it is a common practice to initiate anticoagulation in patients with sinus rhythm in situations where echocardiographic assessment of atrial activity demonstrates minimal or absent mechanical activity (reflected by low trans-mitral A wave velocity) $[7,54,56]$.

\section{Conduction Abnormalities in CA}

Despite the high frequency of atrial involvement with CA, sinus node disease in infrequent [16]. An intracardiac electrophysiology evaluation of sinus node function in 25 patients with AL amyloidosis revealed normal sinus node function in $88 \%$ of those examined [57]. AV conduction delay or bundle branch block is much more common in CA, especially in ATTR-CA [58], and has been shown to herald cardiac decompensation in patients with advanced AL-CA [59]. Conduction abnormalities are as- sociated with tissue infiltration either by direct deposition or by promotion of adjacent myocardial fibrosis [60, 61]. First-degree AV block is often due to a delay in the HisPurkinje system level [16]. In a study investigating electrophysiologic studies in 18 patients with CA the Hisventricular interval was prolonged ( $>55 \mathrm{~ms})$, including 6 patients with a normal QRS duration $(\leq 100 \mathrm{~ms})$ [48].

Pacemakers are indicated for documented heart block or symptomatic bradycardia [62]. Moreover, based on the known natural history of CA and the high incidence of conduction abnormalities, a low threshold for device placement should be considered with the occurrence of presyncope or syncope $[11,16,59]$. When adjusting pacemaker parameters one should aim for atrial-synchronized ventricular pacing, which is vital in patients with CA who are preload dependent [16]. Importantly, under conditions of persistent right ventricular pacing (as in cases where the patient has an underlying complete AV block), interventricular desynchrony may develop, with the risk of further deterioration of the ventricular function. Thus, the initial implantation of cardiac resynchronization therapy should be considered [3].

\section{Ventricular Arrhythmias and Implanted Cardiodefibrillators}

An old study investigating patients with advanced $\mathrm{AL}$ amyloidosis reported an incidence of nonsustained ventricular tachycardias (VT) in $27 \%$ of patients [63], while in a more recent study nonsustained VT were observed in only $0.05 \%$ of the cohort [59]. This discrepancy probably reflects the difference in amyloid burden between study populations rather than a decrease in incidence. AL-CA, has a higher incidence of ventricular arrhythmia compared to that of ATTR-CA [16]. Importantly, the prognostic significance of nonsustained VT in patients with CA has not been established [16], since the rate of sudden cardiac death in patients with AL-CA was similar between those with and without documentation of nonsustained VT [63].

Patients with nonamyloid cardiomyopathies at a high risk for sudden cardiac death, either based on the assessment of severe LV dysfunction or based on the occurrence of sustained ventricular arrhythmias, require an implanted cardiodefibrillator (ICD). Data on the implantation of such devices in patients with amyloid cardiomyopathy is conflicting $[64,65]$. First, as consensus guidelines recommend against ICD placement for the primary prevention of sudden cardiac death in patients with a life expectancy of less than 1 year, the traditional paradigm did not support the implantation of ICD in patients with 
CA [66]. However, this perception is changing due to advances in medical therapy and improved patient outcomes. Second, myocardial scarring and patchy fibrosis that are typical of nonamyloid cardiomyopathies were not observed in CA [16], and the mode of sudden death in CA is frequently pulseless electrical activity (electromechanical dissociation), a rhythm that is not amenable to defibrillation therapy $[59,63,67]$.

Nevertheless, in small cohorts of patients with CA who underwent ICD implantation, mostly for the primary prevention of sudden cardiac death, appropriate ICD therapies were common (7-30\%), with successful termination of the arrhythmias in the majority of cases $[61,65$, 68]. Another interesting observation was the tendency for the first ICD therapy to occur within the first year after ICD implantation [65]. Notably, appropriate ICD therapy does not necessarily translate into an overall survival benefit $[61,67]$, and thus a careful selection of patients is recommended [68].

Based on current consensus guidelines [66], ICD should be considered in patients with AL amyloidosis or hereditary ATTR amyloidosis who experience ventricular arrhythmias associated with hemodynamic instability and have a predicted life expectancy of $>1$ year. No recommendations were made regarding the implantation of ICD for primary prophylaxis [66], yet it may have a role in patients being considered for HT.

\section{Other Cardiac Manifestations}

Amyloid deposits are usually extracellular surrounding the myocytes, although they may be found in small intramural coronary arteries causing ischemia and angina pectoris despite normal epicardial coronaries [7, 42, 69]. As in other diseases causing microvascular dysfunction, there is no evidence supporting the initiation of antiplatelet treatment based solely on this findings [70]. Characteristically, the valves are usually thickened with a common finding of mild to moderate valvular regurgitation. Small pericardial effusions are frequent although large pericardial effusions or tamponade are rare.

\section{Orthostatic Hypotension}

Low to normal blood pressure in a previously hypertensive patient is a clinical clue to suggest possible CA. The blood pressure in CA is frequently low both due to a reduced cardiac output and due to abnormal autonomic nervous system function. Orthostatic hypotension (defined as a decrease in systolic blood pressure of $20 \mathrm{~mm} \mathrm{Hg}$ or a decrease in diastolic blood pressure of $10 \mathrm{~mm} \mathrm{Hg}$ within 3 min of standing) is common and it is a possible and easy to rule out cause for syncope in patients with CA.

The management of postural hypotension involves lifestyle and pharmacological interventions. Patients should be advised to slowly change from a supine to an upright posture and measures to avoid dehydration should be undertaken.

Fludorcortisone should be avoided in patients with CA due to its tendency to cause fluid retention and exacerbate heart failure. Midodrine, an $\alpha-1$ adrenergic stimulant, is the recommended alternative producing an increase in vascular tone [13]. Possible side effects are supine hypertension and urinary retention.

\section{Cardiac Side Effects of Amyloid-Targeted Therapies}

Bortezomib, a proteasome inhibitor, is a well-tolerated drug that despite initial reports of cardiotoxicity (US package insert) was not found to increase the risk of cardiac events or venous thromboembolism in a large metaanalysis [71]. However, the proteasome inhibitor carfilzomib does carry a significant risk of cardiovascular toxicity [72].Itsreported possiblesideeffectsarehypertension, heart failure, and ischemic heart disease. With cessation of carfilzomib and initiation of guideline-directed medical therapy, carfilzomib-associated cardiotoxicity is largely reversible.

The majority of cardiovascular-related toxicities of the immunomodulatory drugs (lenalidomide and pomalidomide) are thrombotic in etiology, including both venous and arterial thromboembolism [73]. The FDA has issued a black box warning for increased arterial thromboembolic events with lenalidomide. According to the consensus statement from the International Myeloma Working Group, patients receiving immunomodulatory drugs should be administered appropriate thromboprophylaxis (either antiplatelet or anticoagulation pharmacotherapy) based on their individual risk factors for the first 4 to 6 months of treatment [74]. In a recent phase 2 pilot study the non-vitamin $\mathrm{K}$ oral anticoagulant apixaban was used for thromboprophylaxis in multiple myeloma patients who were receiving immunomodulatory drugs with promising results [75]. Practically, thromboprophylaxis in often maintained while the risk for thromboembolism remains high, and as long as it is tolerated by the patient, avoiding bleeding complications. 
Furthermore, lenalidomide may cause a paradoxical elevation in BNP or NT-proBNP along with a clinical deterioration despite hematologic improvement; the mechanism for this discrepancy is unknown $[7,76]$. Therefore, lenalidomide should not be used as first-line therapy in patients with cardiac involvement [77].

As discussed, peripheral edema is common in patients with CA and several drugs may also contribute to this complication. Dexamethasone-related fluid retention is common and necessitates a slow uptitration of the dosage [7]. Diflunisal which slows ATTR polyneuropathy progression may cause fluid retention due to its effect as a nonsteroidal anti-inflammatory drug [78].

\section{Summary}

Cardiac involvement in systemic amyloidosis has major prognostic implications. The management of amyloid-induced heart failure and arrhythmias differs from that for nonamyloid cardiomyopathies, and proper management is imperative both to the reduction of cardiovascular morbidity and mortality and to the optimal administration of amyloid-targeted therapies. Finally, a coordinated multidisciplinary care is of prime important in treating CA patients.

\section{Disclosure Statement}

The authors have no conflict of interests to declare.

\section{Funding Sources}

None.

\section{Author Contributions}

O.I.B.Z. drafted this paper, and R.K. critically revised this paper.

\section{References}

1 Shi J, Guan J, Jiang B, Brenner DA, Del Monte F, Ward JE, et al. Amyloidogenic light chains induce cardiomyocyte contractile dysfunction and apoptosis via a non-canonical p38alpha MAPK pathway. Proc Natl Acad Sci USA. 2010 Mar;107(9):4188-93.

2 Brenner DA, Jain M, Pimentel DR, Wang B, Connors LH, Skinner M, et al. Human amyloidogenic light chains directly impair cardiomyocyte function through an increase in cellular oxidant stress. Circ Res. 2004 Apr;94(8): 1008-10.

3 Ponikowski P, Voors AA, Anker SD, Bueno H, Cleland JG, Coats AJ, et al.; Authors/ Task Force Members; Document Reviewers. 2016 ESC Guidelines for the diagnosis and treatment of acute and chronic heart failure: the Task Force for the diagnosis and treatment of acute and chronic heart failure of the European Society of Cardiology (ESC). Developed with the special contribution of the Heart Failure Association (HFA) of the ESC. Eur J Heart Fail. 2016 Aug; 18(8): 891-975.

4 Mesquita ET, Jorge AJ, Souza CV, Andrade TR. Cardiac Amyloidosis and its New Clinical Phenotype: Heart Failure with Preserved Ejection Fraction. Arq Bras Cardiol. 2017 Jul; 109(1):71-80.

5 Sperry BW, Jones BM, Vranian MN, Hanna M, Jaber WA. Recognizing Transthyretin Cardiac Amyloidosis in Patients With Aortic Stenosis: impact on Prognosis. JACC Cardiovasc Imaging. 2016 Jul;9(7):904-6.

6 Vermeer AM, Janssen A, Boorsma PC, Mannens MM, Wilde AA, Christiaans I. Trans- thyretin amyloidosis: a phenocopy of hypertrophic cardiomyopathy. Amyloid. 2017 Jun; 24(2):87-91.

7 Falk RH, Alexander KM, Liao R, Dorbala S. AL (Light-Chain) Cardiac Amyloidosis: A Review of Diagnosis and Therapy. J Am Coll Cardiol. 2016 Sep;68(12):1323-41.

8 Dorbala S, Cuddy S, Falk RH. How to Image Cardiac Amyloidosis: A Practical Approach. JACC Cardiovasc Imaging. 2019 Oct;S1936878X(19)30713-2.

9 Abdalla I, Murray RD, Lee JC, Stewart WJ, Tajik AJ, Klein AL. Duration of pulmonary venous atrial reversal flow velocity and mitral inflow a wave: new measure of severity of cardiac amyloidosis. J Am Soc Echocardiogr. 1998 Dec;11(12):1125-33.

10 Castaño A, Narotsky DL, Hamid N, Khalique OK, Morgenstern R, DeLuca A, et al. Unveiling transthyretin cardiac amyloidosis and its predictors among elderly patients with severe aortic stenosis undergoing transcatheter aortic valve replacement. Eur Heart J. 2017 Oct; 38(38):2879-87.

11 Witteles RM, Liedtke M. AL amyloidosis for the cardiologist and oncologist: epidemiology, diagnosis, and management. JACC Cardiooncol. 2019;1(1):117-30.

12 Palladini G, Merlini G. What is new in diagnosis and management of light chain amyloidosis? Blood. 2016 Jul;128(2):159-68.

13 Wechalekar AD, Gillmore JD, Bird J, Cavenagh J, Hawkins S, Kazmi M, et al.; BCSH Committee. Guidelines on the management of AL amyloidosis. Br J Haematol. 2015 Jan; 168(2):186-206.
14 Pfeffer MA, Claggett B, Assmann SF, Boineau $\mathrm{R}$, Anand IS, Clausell N, et al. Regional variation in patients and outcomes in the Treatment of Preserved Cardiac Function Heart Failure With an Aldosterone Antagonist (TOPCAT) trial. Circulation. 2015 Jan; 131(1):34-42.

15 Merlini G, Dispenzieri A, Sanchorawala V, Schönland SO, Palladini G, Hawkins PN, et al. Systemic immunoglobulin light chain amyloidosis. Nat Rev Dis Primers. 2018 Oct;4(1): 38.

16 John R. Arrythmias in cardiac amyloidosis. J Innov Card Rhythm Manag. 2018;9:3051-7.

17 Muchtar E, Buadi FK, Dispenzieri A, Gertz MA. Immunoglobulin Light-Chain Amyloidosis: From Basics to New Developments in Diagnosis, Prognosis and Therapy. Acta Haematol. 2016;135(3):172-90.

18 Gertz MA, Skinner M, Connors LH, Falk RH, Cohen AS, Kyle RA. Selective binding of nifedipine to amyloid fibrils. Am J Cardiol. 1985 Jun;55(13 Pt 1):1646.

19 Gertz MA, Falk RH, Skinner M, Cohen AS, Kyle RA. Worsening of congestive heart failure in amyloid heart disease treated by calcium channel-blocking agents. Am J Cardiol. 1985 Jun;55(13 Pt 1):1645.

20 Donnelly JP, Hanna M, Sperry BW, Seitz WH Jr. Carpal Tunnel Syndrome: A Potential Early, Red-Flag Sign of Amyloidosis. J Hand Surg Am. 2019 Oct;44(10):868-76.

21 Ward JE, Ren R, Toraldo G, Soohoo P, Guan J, O'Hara C, et al. Doxycycline reduces fibril formation in a transgenic mouse model of AL amyloidosis. Blood. 2011 Dec;118(25):6610-7. 
22 Cardoso I, Martins D, Ribeiro T, Merlini G, Saraiva MJ. Synergy of combined doxycycline/TUDCA treatment in lowering Transthyretin deposition and associated biomarkers: studies in FAP mouse models. J Transl Med. 2010 Jul;8(1):74.

23 Wechalekar AD, Whelan C. Encouraging impact of doxycycline on early mortality in cardiac light chain (AL) amyloidosis. Blood Cancer J. 2017 Mar;7(3):e546.

24 Obici L, Cortese A, Lozza A, Lucchetti J, Gobbi M, Palladini G, et al. Doxycycline plus tauroursodeoxycholic acid for transthyretin amyloidosis: a phase II study. Amyloid. 2012 Jun; 19(sup1 Suppl 1):34-6.

25 Witteles RM. Doxycycline and Ursodiol for ATTR Amyloidosis: Not Ready for Prime Time. J Card Fail. 2019 Mar;25(3):154-5.

26 Karlstedt E, Jimenez-Zepeda V, Howlett JG, White JA, Fine NM. Clinical Experience With the Use of Doxycycline and Ursodeoxycholic Acid for the Treatment of Transthyretin Cardiac Amyloidosis. J Card Fail. 2019 Mar; 25(3):147-53.

27 Castaño A, DeLuca A, Weinberg R, Pozniakoff T, Blaner WS, Pirmohamed A, et al. Serial scanning with technetium pyrophosphate $(99 \mathrm{mTc}-$ PYP) in advanced ATTR cardiac amyloidosis. J Nucl Cardiol. 2016 Dec;23(6):1355-63.

28 Adams D, Gonzalez-Duarte A, O'Riordan WD, Yang CC, Ueda M, Kristen AV, et al. Patisiran, an RNAi Therapeutic, for Hereditary Transthyretin Amyloidosis. N Engl J Med. 2018 Jul;379(1):11-21.

29 Koyama J, Falk RH. Prognostic significance of strain Doppler imaging in light-chain amyloidosis. JACC Cardiovasc Imaging. 2010 Apr; 3(4):333-42.

30 Dorbala S, Ando Y, Bokhari S, Dispenzieri A, Falk RH, Ferrari VA, et al. ASNC/AHA/ ASE/EANM/HFSA/ISA/SCMR/SNMMI Expert Consensus Recommendations for Multimodality Imaging in Cardiac Amyloidosis: Part 1 of 2-Evidence Base and Standardized Methods of Imaging. J Card Fail. 2019 Nov; 25(11):e1-39.

31 Palladini G, Barassi A, Klersy C, Pacciolla R, Milani P, Sarais G, et al. The combination of high-sensitivity cardiac troponin $\mathrm{T}$ (hs-cTnT) at presentation and changes in N-terminal natriuretic peptide type B (NT-proBNP) after chemotherapy best predicts survival in AL amyloidosis. Blood. 2010 Nov;116(18):3426-30.

32 Grogan M, Scott CG, Kyle RA, Zeldenrust SR, Gertz MA, Lin G, et al. Natural history of wild-type transthyretin cardiac amyloidosis and risk stratification using a novel staging system. J Am Coll Cardiol. 2016 Sep;68(10): 1014-20.

33 Gillmore JD, Damy T, Fontana M, Hutchinson M, Lachmann HJ, Martinez-Naharro A, et al. A new staging system for cardiac transthyretin amyloidosis. Eur Heart J. 2018 Aug; 39(30):2799-806

34 Comenzo RL, Reece D, Palladini G, Seldin D, Sanchorawala V, Landau H, et al. Consensus guidelines for the conduct and reporting of clinical trials in systemic light-chain amyloidosis. Leukemia. 2012 Nov;26(11):2317-25.

35 Swiecicki PL, Edwards BS, Kushwaha SS, Dispenzieri A, Park SJ, Gertz MA. Left ventricular device implantation for advanced cardiac amyloidosis. J Heart Lung Transplant. 2013 May;32(5):563-8.

36 Maurer MS, Elliott P, Comenzo R, Semigran M, Rapezzi C. Addressing Common Questions Encountered in the Diagnosis and Management of Cardiac Amyloidosis. Circulation. 2017 Apr;135(14):1357-77.

37 Sousa M, Monohan G, Rajagopalan N, Grigorian A, Guglin M. Heart transplantation in cardiac amyloidosis. Heart Fail Rev. 2017 May;22(3):317-27.

38 Grogan M, Gertz M, McCurdy A, Roeker L, Kyle R, Kushwaha S, et al. Long term outcomes of cardiac transplant for immunoglobulin light chain amyloidosis: The Mayo Clinic experience. World J Transplant. 2016 Jun; 6(2):380-8.

39 Davis MK, Lee PH, Witteles RM. Changing outcomes after heart transplantation in patients with amyloid cardiomyopathy. J Heart Lung Transplant. 2015 May;34(5):658-66.

40 Mehra MR, Canter CE, Hannan MM, Semigran MJ, Uber PA, Baran DA, et al.; International Society for Heart Lung Transplantation (ISHLT) Infectious Diseases, Pediatric and Heart Failure and Transplantation Councils. The 2016 International Society for Heart Lung Transplantation listing criteria for heart transplantation: A 10-year update. J Heart Lung Transplant. 2016 Jan;35(1):1-23.

41 Lacy MQ, Dispenzieri A, Hayman SR, Kumar S, Kyle RA, Rajkumar SV, et al. Autologous stem cell transplant after heart transplant for light chain (Al) amyloid cardiomyopathy. J Heart Lung Transplant. 2008 Aug;27(8):823-9.

42 Donnelly JP, Hanna M. Cardiac amyloidosis: an update on diagnosis and treatment. Cleve Clin J Med. 2017 Dec;84(12 Suppl 3):12-26.

43 Longhi S, Quarta CC, Milandri A, Lorenzini M, Gagliardi C, Manuzzi L, et al. Atrial fibrillation in amyloidotic cardiomyopathy: prevalence, incidence, risk factors and prognostic role. Amyloid. 2015;22(3):147-55.

44 Falk RH, Dubrey SW. Amyloid heart disease. Prog Cardiovasc Dis. 2010 Jan-Feb;52(4): 347-61.

45 Rubinow A, Skinner M, Cohen AS. Digoxin sensitivity in amyloid cardiomyopathy. Circulation. 1981 Jun;63(6):1285-8.

46 Muchtar E, Gertz MA, Kumar SK, Lin G, Boilson B, Clavell A, et al. Digoxin use in systemic light-chain (AL) amyloidosis: contra-indicated or cautious use? Amyloid. 2018 Jun; 25(2):86-92.

47 El-Am EA, Dispenzieri A, Melduni RM, Ammash NM, White RD, Hodge DO, et al. Direct Current Cardioversion of Atrial Arrhythmias in Adults With Cardiac Amyloidosis. J Am Coll Cardiol. 2019 Feb;73(5):589-97.

48 Barbhaiya CR, Kumar S, Baldinger SH, Michaud GF, Stevenson WG, Falk R, et al. Electrophysiologic assessment of conduction ab- normalities and atrial arrhythmias associated with amyloid cardiomyopathy. Heart Rhythm. 2016 Feb;13(2):383-90.

49 Tan NY, Mohsin Y, Hodge DO, Lacy MQ, Packer DL, Dispenzieri A, et al. Catheter Ablation for Atrial Arrhythmias in Patients With Cardiac Amyloidosis. J Cardiovasc Electrophysiol. 2016 Oct;27(10):1167-73.

50 Feng D, Edwards WD, Oh JK, Chandrasekaran K, Grogan M, Martinez MW, et al. Intracardiac thrombosis and embolism in patients with cardiac amyloidosis. Circulation. 2007 Nov; 116(21):2420-6.

51 Sucker C, Hetzel GR, Grabensee B, Stockschlaeder M, Scharf RE. Amyloidosis and bleeding: pathophysiology, diagnosis, and therapy. Am J Kidney Dis. 2006 Jun;47(6):947-55.

52 Feng D, Syed IS, Martinez M, Oh JK, Jaffe AS, Grogan M, et al. Intracardiac thrombosis and anticoagulation therapy in cardiac amyloidosis. Circulation. 2009 May;119(18):2490-7.

53 Anderson KP. Cardiac Amyloidosis and the Risks of Cardioversion. J Am Coll Cardiol. 2019 Feb;73(5):598-601.

54 Meier-Ewert HK, Sanchorawala V, Berk JL, Ruberg FL. Cardiac amyloidosis: evolving approach to diagnosis and management. Curr Treat Options Cardiovasc Med. 2011 Dec; 13(6):528-42.

55 Dubrey S, Pollak A, Skinner M, Falk RH. Atrial thrombi occurring during sinus rhythm in cardiac amyloidosis: evidence for atrial electromechanical dissociation. Br Heart J. 1995 Nov;74(5):541-4.

56 Grogan M, Dispenzieri A. Natural history and therapy of AL cardiac amyloidosis. Heart Fail Rev. 2015 Mar;20(2):155-62.

57 Reisinger J, Dubrey SW, Lavalley M, Skinner M, Falk RH. Electrophysiologic abnormalities in AL (primary) amyloidosis with cardiac involvement. J Am Coll Cardiol. 1997 Oct;30(4):1046-51.

58 Sperry BW, Vranian MN, Hachamovitch R, Joshi H, McCarthy M, Ikram A, et al. Are classic predictors of voltage valid in cardiac amyloidosis? A contemporary analysis of electrocardiographic findings. Int J Cardiol. $2016 \mathrm{Jul}$; 214:477-81.

59 Sayed RH, Rogers D, Khan F, Wechalekar AD, Lachmann HJ, Fontana M, et al. A study of implanted cardiac rhythm recorders in advanced cardiac AL amyloidosis. Eur Heart J. 2015 May;36(18):1098-105.

60 Ridolfi RL, Bulkley BH, Hutchins GM. The conduction system in cardiac amyloidosis. Clinical and pathologic features of 23 patients. Am J Med. 1977 May;62(5):677-86.

61 Lin G, Dispenzieri A, Kyle R, Grogan M, Brady PA. Implantable cardioverter defibrillators in patients with cardiac amyloidosis. J Cardiovasc Electrophysiol. 2013 Jul;24(7):793-8.

62 Castaño A, Drachman BM, Judge D, Maurer MS. Natural history and therapy of TTR-cardiac amyloidosis: emerging disease-modifying therapies from organ transplantation to stabilizer and silencer drugs. Heart Fail Rev. 2015 Mar;20(2):163-78. 
63 Dubrey SW, Cha K, Anderson J, Chamarthi B, Reisinger J, Skinner M, et al. The clinical features of immunoglobulin light-chain (AL) amyloidosis with heart involvement. QJM. 1998 Feb;91(2):141-57.

64 Patel KS, Hawkins PN, Whelan CJ, Gillmore JD. Life-saving implantable cardioverter defibrillator therapy in cardiac AL amyloidosis. BMJ Case Rep 2014;2014:bcr2014206600.

65 Hamon D, Algalarrondo V, Gandjbakhch E, Extramiana F, Marijon E, Elbaz N, et al. Outcome and incidence of appropriate implantable cardioverter-defibrillator therapy in patients with cardiac amyloidosis. Int J Cardiol. 2016 Nov;222:562-8.

66 Priori SG, Blomström-Lundqvist C, Mazzanti A, Blom N, Borggrefe M, Camm J, et al.; ESC Scientific Document Group. 2015 ESC Guidelines for the management of patients with ventricular arrhythmias and the prevention of sudden cardiac death: The Task Force for the Management of Patients with Ventricular Arrhythmias and the Prevention of Sudden Cardiac Death of the European Society of Cardiology (ESC). Endorsed by: Association for European Paediatric and Congenital Cardiology (AEPC). Eur Heart J. 2015 Nov;36(41): 2793-867.

67 Kristen AV, Dengler TJ, Hegenbart U, Schonland SO, Goldschmidt H, Sack FU, et al. Prophylactic implantation of cardioverter-defibrillator in patients with severe cardiac amyloidosis and high risk for sudden cardiac death. Heart Rhythm. 2008 Feb;5(2):235-40.
68 Varr BC, Zarafshar S, Coakley T, Liedtke M, Lafayette RA, Arai S, et al. Implantable cardioverter-defibrillator placement in patients with cardiac amyloidosis. Heart Rhythm. 2014 Jan;11(1):158-62.

69 Miani D, Rocco M, Alberti E, Spedicato L, Fioretti PM. Amyloidosis of epicardial and intramural coronary arteries as an unusual cause of myocardial infarction and refractory angina pectoris. Ital Heart J. 2002 Aug;3(8): $479-82$.

70 Agewall S, Beltrame JF, Reynolds HR, Niessner A, Rosano G, Caforio AL, et al.; WG on Cardiovascular Pharmacotherapy. ESC working group position paper on myocardial infarction with non-obstructive coronary arteries. Eur Heart J. 2017 Jan;38(3):143-53.

71 Xiao Y, Yin J, Wei J, Shang Z. Incidence and risk of cardiotoxicity associated with bortezomib in the treatment of cancer: a systematic review and meta-analysis. PLoS One. 2014 Jan;9(1):e87671.

72 Bringhen S, Milan A, D'Agostino M, Ferri C, Wäsch R, Gay F, et al. Prevention, monitoring and treatment of cardiovascular adverse events in myeloma patients receiving carfilzomib A consensus paper by the European Myeloma Network and the Italian Society of $\mathrm{Ar}$ terial Hypertension. J Intern Med. 2019 Jul; 286(1):63-74.

73 Li W, Garcia D, Cornell RF, Gailani D, Laubach J, Maglio ME, et al. Cardiovascular and Thrombotic Complications of Novel Multiple Myeloma Therapies: A Review. JAMA Oncol. 2017 Jul;3(7):980-8.
74 Palumbo A, Rajkumar SV, San Miguel JF, Larocca A, Niesvizky R, Morgan G, et al. International Myeloma Working Group consensus statement for the management, treatment, and supportive care of patients with myeloma not eligible for standard autologous stem-cell transplantation. J Clin Oncol. 2014 Feb;32(6):587-600.

75 Pegourie B, Karlin L, Benboubker L, OrsiniPiocelle F, Tiab M, Auger-Quittet S, et al.; IFM Group. Apixaban for the prevention of thromboembolism in immunomodulatorytreated myeloma patients: Myelaxat, a phase 2 pilot study. Am J Hematol. 2019 Jun;94(6): 635-40.

76 Dispenzieri A, Dingli D, Kumar SK, Rajkumar SV, Lacy MQ, Hayman S, et al. Discordance between serum cardiac biomarker and immunoglobulin-free light-chain response in patients with immunoglobulin light-chain amyloidosis treated with immune modulatory drugs. Am J Hematol. 2010 Oct;85(10): 757-9.

77 Gertz MA. Immunoglobulin light chain amyloidosis: 2018 Update on diagnosis, prognosis, and treatment. Am J Hematol. 2018 Sep; 93(9):1169-80.

78 Berk JL, Suhr OB, Obici L, Sekijima Y, Zeldenrust SR, Yamashita T, et al.; Diflunisal Trial Consortium. Repurposing diflunisal for familial amyloid polyneuropathy: a randomized clinical trial. JAMA. 2013 Dec;310(24): 2658-67. 